\title{
Urinary incontinence in postmenopausal women - causes, symptoms, treatment
}

\author{
Gabriela Kołodyńska ${ }^{1}$, Maciej Zalewski², Krystyna Rożek-Piechura ${ }^{1}$ \\ ${ }^{1}$ Department of Rehabilitation in Internal Diseases, University School of Physical Education, Wroclaw, Poland \\ ${ }^{2}$ Faculty of Health Sciences, Medical University of Wroclaw, Poland
}

\begin{abstract}
Urinary incontinence (UI) is an important social problem that affects more than $50 \%$ of postmenopausal women. The number of patients increases from year to year. According to recent data, UI affects women twice as often as men. This condition occurs in about $20-30 \%$ of young women, $30-40 \%$ in middle age and up to $50 \%$ of women in old age. There are five types of urinary incontinence. The etiology of the problem of incontinence is not fully understood, because the problem can affect men and women of all ages and can be due to many changes in the human body. International Continence Society Guidelines indicate that treatment of urinary incontinence should begin with conservative treatment. Surgical treatment should be used when conservative treatment will not bring positive results. According to guidelines, conservative treatment should include pharmacotherapy, physiotherapy, and behavioral therapy. Numerous scientific reports indicate efficacy of physiotherapy in the treatment of urinary incontinence. Most recent reports indicate that physiotherapy gives a positive result in up to $80 \%$ of patients with stage I or stress urinary incontinence (SUI) and mixed form, and in $50 \%$ of patients with stage II SUI. Urinary incontinence is an interdisciplinary problem because in addition to the sphere directly related to medicine, it also concerns the economic and social spheres. The latest data show that incontinence in postmenopausal women occurs more often than other civilization diseases such as diabetes, hypertension or depression.
\end{abstract}

Key words: physiotherapy, urinary incontinence, treatment.

\section{Introduction}

Menopause is a critical period in the life of every woman. The time of menopausal transition is often marked by metabolic changes that affect the health of a woman. Recent scientific reports indicate that already before the onset of menopause, referred to as the climacteric, it causes many unpleasant symptoms that worsen the quality of life of many women. These symptoms are very often the result of hormonal and metabolic changes and, as a consequence, increase the risk of chronic diseases [1]. Recently, there have been reports that show the influence of menopause on the development of cardiovascular diseases. According to statistics, cardiovascular diseases are the main cause of death in women. Analysis of available literature shows a correlation between the dynamic changes of sex hormones, especially endogenous estradiol and follicle stimulating hormone as well as vasomotor symptoms, and the circulatory system in women [2]. The increased risk of cardiovascular disease is also due to the increase in low-density lipoprotein (LDL) and triglycerides and is associated with the decrease in high-density lipopro- tein $(\mathrm{HDL})$. Weight gain is also significant, which often correlates with the increase in hypertension and diabetes in patients during menopause. Hormonal changes associated with estrogen deficiency may also contribute to the occurrence of osteoporosis. Other symptoms of menopause include hot flushes, sweating (especially at night), irritability, problems with concentration, joint pain, vaginal dryness, as well as urogenital disorders. Among them, incontinence is extremely common [3].

Urinary incontinence (UI) is an important social problem that affects more than $50 \%$ of postmenopausal women [4]. The number of patients increases from year to year, affected by the rapid social development contributing to a sedentary lifestyle. It affects mainly the sedentary nature of work, too frequent use of the car or the lack of time for any physical activity. This trend is particularly evident in the elderly, who often spend their free time watching TV, and they do not practice sport [5]. These factors weaken the overall performance of the body, leading to weakness of the muscles or bones, respiratory disorders and circulatory problems. The result is the emergence of numerous 
pathologies and dysfunctions of the body that cause a significant reduction in quality of life. One common problem that affects postmenopausal women is incontinence. Awareness of women regarding this disease increases from year to year [6]. Nevertheless, many patients still considers incontinence as a natural symptom of aging. It is estimated that in Poland this disease affects over 5 million people. According to recent data, $\mathrm{UI}$ affects women twice as often as men. This condition occurs in about $20-30 \%$ of young women, $30-40 \%$ in middle age and up to $50 \%$ of women in old age [7].

This problem significantly affects the quality of life of affected women. Urinary incontinence negatively affects many aspects of life, significantly reducing the daily functioning associated with work, physical activity or the intimate sphere. Urinary incontinence is the main symptom of genitourinary syndrome of menopause (GSM) and is often associated with sexual dysfunctions. Menopausal urinary tract occurs in over $50 \%$ of menopausal women. GSM is a hypoestrogenic condition with external genital, urological, and sexual implications. This disease causes a number of symptoms including vaginal dryness, insufficient lubrication and discomfort during sexual activity. In addition, after sexual activity, women sometimes observe bleeding and burning and vulvar itching. Patients very often report a decrease in excitement, sexual desire and orgasm, as well as a problem with incontinence. Early detection of the disease and appropriately selected pharmacotherapy and nonpharmacological agents, including physiotherapy, play a fundamental role in improving the quality of life of patients, and also prevent exacerbation of symptoms $[8,9]$.

\section{Definition, types, and etiology of incontinence}

The International Continence Society (ICS) defines urinary incontinence as involuntary uncontrolled leakage of urine due to bladder dysfunction of the locking mechanism. This definition, in force since 2002, and the previous one are different in that this phenomenon does not need to be supported by documentation and testing. The latest ICS report indicates the need for expansion of the definition and information relating to additional symptoms, incidence, risk factors and impact on health and quality of life [10].

There are five types of urinary incontinence. Nevertheless, some authors of scientific reports assign patients to three main categories, only distinguishing stress incontinence, urge incontinence and mixed urinary incontinence. Among the most common urinary incontinence divisions the following stand out [11]:

- Stress urinary incontinence (SUI) - according to some authors, it is the most common type of UI and represents $50 \%$ to $88 \%$ of all types of urinary incontinence. It characterized by leakage of urine, which is caused by an increase in abdominal pressure. Situations that predispose to this condition are primarily sneezing, bending, and lifting weights. SUI arises from weakening of the pelvic floor muscles and failure of complex musculo-ligamentous-fasciocutaneous tissues. Among the most common causes of the disease are childbirth, trauma, hormonal disorders and a reduction in reproductive organs, and operations. Stress urinary incontinence distinguishes between three stages of progression of the disease:

- stage I - symptoms occur only during a major effort, which causes an increase in intra-abdominal pressure. Account should be taken here of sneezing, coughing or laughing;

- stage II - the symptoms appear during moderate exercise such as running, heavy lifting or sports. Produces a moderate increase in intra-abdominal pressure;

- stage III - symptoms are observable with minimal physical exertion and a small increase in intra-abdominal pressure. Urinary incontinence can occur during walking, and also when changing the position from lying down to standing.

- Overactive bladder, urge incontinence (UUI) - it occurs as a result of an imbalance between inhibitory and excitatory mechanisms' detrusor activity which results in a disorder of micturition. It is estimated that $17.4 \%$ of women and $15.6 \%$ of men suffer this ailment. The most common causes include:

- CNS damage above bridge - causing detrusor overactivity while reducing the capacity of the bladder. Most cases result from stroke, dementia and Parkinson's disease;

- spinal cord at the level of S2-S4 - at this level there is a micturition center. In case of damage to it the patient loses the capacity for reflex emptying. The bladder is autonomous in relation to the nervous system and has lost the ability to effectively cause shrinkage of residual urine;

- spinal cord above the level of S2-S4 - urination reflex depends on the Parasympathetic nervous system, and the bladder compresses effectively, but is done rather unexpectedly and involuntarily [12].

- Overflow incontinence - symptoms are present when the bladder accumulates a urine volume greater than the maximum capacity of the bladder. As a result, the pressure causes the urine to flow through the urethra. This situation may occur as a result of the existence of obstruction, e.g. prostate hypertrophy or in the event of neurological disturbances.

- Mixed urinary incontinence (MUI) - it is a combination of symptoms of UI with overactive bladder.

- Transient incontinence - refers to the situation where the symptoms are short-lived [13, 14].

The etiology of the problem of incontinence is not fully understood, because the problem can affect 
men and women of all ages and can be due to many changes in the human body. Factors which predispose to the occurrence UI may have different bases $[15,16]$. Among the most important, genetic factor stands out, because as noted, this factor is higher in women whose ancestors suffered from incontinence. Age is also very important. The risk increases in direct proportion to age. In postmenopausal women the incidence of disease is doubled. This is primarily due to the fact that urinary tract infection reduces the level of estrogen in the blood. As a result, this situation causes the reduction of the urethra. Sometimes the urethra is shortened to $1-2 \mathrm{~cm}$. Moreover, very often it is followed by muscle weakness and also the reconstruction of the bladder and the muscles responsible for the excretion of urine. A very important factor is the number of pregnancies and births, particularly those induced with oxytocin. It is suggested that caesarean deliveries are safer in terms of occurrence of UI. The probability of disease increases also when the weight of the fetus exceeds $4 \mathrm{~kg}$. Another important factor is obesity. The most dangerous is abdominal obesity. Studies show that obese women are 4-5 times more likely to suffer from incontinence than those of normal weight. Among other factors which may affect the occurrence of UI that are also ignored or improperly treated are urinary tract infections, chronic constipation, diabetic neuropathy, Parkinson's disease, multiple sclerosis, polyradiculopathy, drugs or medications for example diuretics, antihypertensive and anxiolytic. Another risk is chronic respiratory diseases, particularly those extending from a cough, which causes an increase in abdominal pressure, for example chronic obstructive pulmonary disease $[17,18]$.

\section{Treatment of urinary incontinence}

International Continence Society Guidelines indicate that treatment of UI should begin with conservative therapy [19]. Surgical treatment should be used when conservative treatment will not bring positive results. Initially, it is used only in patients with degree II and III of UI. According to conservative treatment guidelines it should include pharmacotherapy, physiotherapy, and behavioral therapy. Pharmacotherapy embraces both local and systemic therapy. In the local treatment estrogens and the adrenergic receptors medicines are usually used to enhance the tissue turgor within the vestibule. In addition, local treatment is recommended. Anticholinergic agents are responsible for blocking the muscarinic receptors located in the bladder. The International Continence Society recommends systemic use of duloxetine, but the Polish Urogynecology Society does not recommend the treatment of SUI with duloxetine. This is due to the fact that duloxetine does not cure incontinence, but only reduces the symptoms. Duloxetine has a number of side effects with respect to the gastrointestinal and central nervous system. Moreover, in all types of UI one is recommended to use sedatives and an antihistaminic [20].

Regardless of the type or severity of the disease, it is recommended that patients have behavioral therapy, which involves a change in lifestyle. Obese persons' treatment of UI should start with weight reduction of at least 5\%. Obesity and overweight are risk factors for SUI in women. Recent scientific reports indicate that weight loss of $5 \%$ causes a reduction of objective symptoms of SUI. It is also important to limit the consumption of beverages that contain caffeine, alcohol or drinks with gas contributing to increased pressure on the bladder, as they irritate the delicate mucous membranes lining its interior. Not without significance is to control the time and quantity of fluid intake. It is also recommended that patients with incontinence cease practicing sports that adversely affect the pelvic floor muscles such as exercises on trampolines. It is also important to introduce bladder training, which should include the reduction of the frequency of visits to the toilet and exercises involving the control stream during urination. Commonly also recommended are therapy pessaries or rollers, balls, and cubes, which should be used for all patients regardless of the forms of treatment $[21,22]$.

Numerous scientific reports indicate efficacy of physiotherapy in the treatment of UI. Most recent reports indicate that a physiotherapy procedure gives a positive result in up to $80 \%$ of patients with stage I or SUI and mixed form, and in $50 \%$ of patients with stage II SUI. Interdisciplinary Polish Society Guidelines recommend the use of urogynecological pelvic floor physiotherapy longer as prevention in older women and in pregnancy and childbirth. It is now believed that the most effective form of therapy is a combination of electrical stimulation of the pelvic floor muscle training with the active muscle. According to many authors, most effective here is biofeedback training, which allows patients to perform a visual inspection of the muscle training. In addition, all patients are advised to perform pelvic floor exercises, which will result in the strengthen their weakened muscles $[23,24]$.

Surgical treatment should be introduced only after exhausting all possibilities of conservative therapy. Each operation must be preceded by a conversation with the patient with the presentation of its purpose and reason for the surgery, as well as its advantages and disadvantages. The most common surgery is performed in cases of SUI. There are more than 150 different surgical techniques. The method is always selected by the physician on an individual basis for each individual case. This multitude proves that there is no perfect and universal method for all. Among the most well-known surgical techniques is Burch colposuspension. The Burch method allows the resolution of involuntary voiding of $68.9 \%$ 
to $88 \%$ of patients. The recovery period after surgery is between 1 and 2 weeks for procedures performed laparoscopically and for 2 to 4 weeks for patients undergoing the technique of opening of the abdominal cavity. Currently, the "first line therapy" surgical treatment of SUI is considered tension-free vaginal tape (TVT). TVT is very effective in the treatment of stress urinary incontinence. It has low invasiveness and is characterized by a rapid return of patients to health and long-term effectiveness. Another type of surgical treatment is the use of bulking agents. There is no scientific evidence yet that this method would show long-term effectiveness $[25,26]$.

More recently, scientific reports have appeared that concern the change in the quality of life and sexual function of women undergoing surgery in SUI. It is common knowledge that patients with UI negatively assess the quality of their life, and their sex life often does not exist, which in the end often contributes to the breakdown of marriages and separation from life in society. The results of the conducted research clearly show that the quality of women's life after surgical procedures improves significantly. In addition, their well-being, self-esteem and self-confidence are improved. All this makes sexual functions also improve [27-29].

\section{Conclusions}

Urinary incontinence is an interdisciplinary problem because in addition to the sphere directly related to medicine, it also concerns the economic and social spheres. The latest data show that incontinence in postmenopausal women occurs more often than other civilization diseases such as diabetes, hypertension or depression. Statistical data show that only $1 / 3$ of patients undertake treatment attempts. Unfortunately, often people affected by this problem believe that the only form of treatment is surgery and for obvious reasons they are afraid to undergo it. Therefore, it seems necessary to develop standards for physiotherapeutic treatment in the field of urinary incontinence treatment, and thus to search for the most effective and least invasive therapeutic methods.

\section{Disclosure}

The authors report no conflict of interest.

\section{References}

1. Blümel JE, Lavín P, Vallejo MS, Sarrá S. Menopause or climacteric, just a semantic discussion or has it clinical implications? Climacteric 2014; 17: 235-241.

2. El Khoudary SR, Thurston RC. Cardiovascular implications of the menopause transition: endogenous sex hormones and vasomotor symptoms. Obstet Gynecol Clin North Am 2018; 45: 641-661.
3. Vitale SG, Caruso S, Rapisarda AMC, et al. Isoflavones, calcium, vitamin $D$ and inulin improve quality of life, sexual function, body composition and metabolic parameters in menopausal women: result from a prospective, randomized, placebo-controlled, parallel-group study. Prz Menopauzalny 2018; 17: 32-38.

4. Barnaś E, Barańska E, Gawlik B, Zych B. Factors most significantly affecting quality of life in women with urinary incontinence. HYGEIA Public Health 2015; 50: 643-648.

5. Gücük $S$, Gücük A. Approach to urinary incontinence in the elderly in primary care: a mini review. Gerontol Geriatrics 2017; 1: 1-4.

6. Özlü A, Yıldız N, Öztekin Ö. Comparison of the efficacy of perineal and intravaginal biofeedback assisted pelvic floor muscle exercises in women with urodynamic stress urinary incontinence. Neurourol Urodyn 2017; 36: 2132-2141.

7. Syan R, Brucker B. Guideline of guidelines: urinary incontinence. BJU Int 2016; 117: 20-33.

8. Gandhi J, Chen A, Dagur G, et al. Genitourinary syndrome of menopause: an overview of clinical manifestations, pathophysiology, etiology, evaluation, and management. Am J Obstet Gynecol 2016; 215: 704-711.

9. Paszkowski T. Zastosowanie laseroterapii w leczeniu urogenitalnego zespołu menopauzalnego. Opis przypadku. Forum Położnictwa i Ginekologii 2016; 29: 13-19.

10. Fiodorenko-Dumas Ż, Paprocka-Borowicz M. Postępowanie fizjoterapeutyczne w nietrzymaniu moczu. MONZ 2014; 20: 12-16.

11. Hrycyna M, Strupińska-Thor E. Ćwiczenia wzmacniające mięśnie dna miednicy mniejszej $u$ kobiet $z$ wysitkowym nietrzymaniem moczu. Zeszyty Naukowe WSKFiT 2016; 11: 21-28.

12. Imamura $M$, Jenkinson $D$, Wallace $S$, et al. Conservative treatment options for women with stress urinary incontinence: clinical update. Br J Gen Pract 2013; 63: 218-220.

13. Moroni RM, Magnani PS, Haddad JM, et al. Conservative treatment of stress urinary incontinence: a systematic review with meta-analysis of randomized controlled trials. Rev Bras Ginecol Obstet 2016; 38: 97-111.

14. Turkan A, Inci Y, Fazli D. The short-term effects of physical therapy in different intensities of urodynamic stress incontinence. Gynecol Obstet Invest 2005; 59: 43-48

15. Newman DK. Pelvic floor muscle rehabilitation using biofeedback. Urol Nurs 2014; 34: 193-202.

16. Pereira C, Castiglione M, Kasawara K. Effects of physiotherapy treatment for urinary incontinence in patient with multiple sclerosis. J Phys Ther Sci 2017; 29: 1259-1263.

17. Reilly ETC, Freeman RM, Waterfield MR. Prevention of postpartum stress incontinence in primigravidae with increased bladder neck mobility: a randomized controlled trial of antenatal pelvic floor exercises. Br J Obstet Gynaecol 2002; 109: 68-76.

18. Terlikowski R, Dobrzycka B, Kinalski $M$, et al. Transvaginal electrical stimulation with surface-EMG biofeedback in managing stress urinary incontinence in women of premenopausal age: a double-blind, placebocontrolled, randomized clinical trial. Int Urogynecol J 2013; 24: 16311638.

19. Syan R, Brucker B. Guideline of guidelines: urinary incontinence. BJU Int 2016; 117: 20-33.

20. Bertotto A, Schvartzman R, Uchôa S, Wender MCO. Effect of electromyographic biofeedback as an add-on to pelvic floor muscle exercises on neuromuscular outcomes and quality of life in postmenopausal women with stress urinary incontinence: A randomized controlled trial. Neurourol Urodyn 2017; 36: 2142-2147.

21. Delft K, Thakar R, Sultan AH. Pelvic floor muscle contractility: digital assessment vs transperineal ultrasound. Ultrasound Obstet Gynecol 2015; 45: 217-222.

22. Griffiths D, Clarkson B, Tadic SD, Resnick NM. Brain mechanisms underlying urge incontinence and its response to pelvic floor muscle training. J Urol 2015; 194: 708-715.

23. Meyer P. Algorithms and urinary incontinence in the elderly. Assessment, treatment, recommendations and levels of evidence. Review Prog Urol 2017; 27: 111-145.

24. Opara J, Socha T, Prajsner A, Poświata A. Fizjoterapia w wysiłkowym nietrzymaniu moczu u kobiet. Część II. Biologiczne sprzężenie zwrotne w wysiłkowym nietrzymaniu moczu. Fizjoterapia 2011; 19: 37-42. 
25. Shen SX, Liu Y. A retrospective study of neuromuscular electrical stimulation for treating women with post-stroke incontinence. Medicine (Baltimore) 2018; 97: e11264.

26. Voorham JC, De Wachter S, Van den Bos TWL, et al. The effect of EMG biofeedback assisted pelvic floor muscle therapy on symptoms of the overactive bladder syndrome in women: a randomized controlled trial. Neurourol Urodyn 2017; 36: 1796-1803.

27. Vitale SG, Caruso S, Rapisarda AM, et al. Biocompatible porcine dermis graft to treat severe cystocele: impact on quality of life and sexuality. Arch Gynecol Obstet 2016; 293: 125-131.

28. Tang X, Zhu L, Liang S, Lang J. Outcome and sexual function after transobturator tape procedure versus tension-free vaginal tape SECUR: a randomized controlled trial. Menopause 2014; 21: 641-645.

29. Caruso S, Cianci S, Vitale SG, et al. Effects of ultralow topic estriol dose on vaginal health and quality of life in postmenopausal women who underwent surgical treatment for pelvic organ prolapse. Menopause 2017; 24: 900-907 